\title{
Bergerac - Les Costes, rue Jean Mace
}

$\mathrm{n}^{\circ} 026010$

\section{Christophe Fourloubey}

\section{(2) OpenEdition}

12 Journals

Édition électronique

URL : http://journals.openedition.org/adlfi/16287

ISSN : 2114-0502

Éditeur

Ministère de la culture

Référence électronique

Christophe Fourloubey, «Bergerac - Les Costes, rue Jean Mace », ADLFI. Archéologie de la France Informations [En ligne], Aquitaine, mis en ligne le 10 février 2016, consulté le 03 mai 2019. URL : http:// journals.openedition.org/adlfi/16287

Ce document a été généré automatiquement le 3 mai 2019.

(c) Ministère de la Culture et de la Communication, CNRS 


\title{
Bergerac - Les Costes, rue Jean Mace
} $\mathrm{n}^{\circ} 026010$

\author{
Christophe Fourloubey
}

Lien Atlas (MCC) :

http://atlas.patrimoines.culture.fr/atlas/trunk/index.php?

ap_theme=DOM_2.01.02\&ap_bbox=0.431;44.804;0.545;44.900

1 Le projet consiste en la subdivision d'une parcelle de $3283 \mathrm{~m}^{2}$ en six lots, destinés à être viabilisés puis vendus en terrains à bâtir.

2 L'emprise se trouve en bordure sud-ouest du plateau de Pécharmant, sur la terrasse Fw qui a scellé - à un peu plus de $1000 \mathrm{~m}$ vers l'est - des indices néolithiques aux Galinoux, et des indices paléolithiques, néolithiques et médiévaux aux Libraires.

3 Les six tranchées de diagnostic représentent une superficie au sol de $218 \mathrm{~m}^{2}$, soit une reconnaissance de 6,6\% du projet.

4 Hormis les quelques débris anthropiques subactuels pris dans les labours, aucun indice archéologique n'a été découvert sur le présent projet.

INDEX

Index géographique : Aquitaine, Dordogne (24), Bergerac

operation Opération préventive de diagnostic (OPD) 
AUTEURS

CHRISTOPHE FOURLOUBEY

Inrap 